\title{
NOVEL LIDAR ALGORITHMS FOR ATMOSPHERIC SLANT- RANGE VISIBILITY, PLANETARY BOUNDARY LAYER HEIGHT, METEOROGICAL PHENOMENA AND ATMOSPHERIC LAYERING MEASUREMENTS
}

\author{
Alexandros Pantazis ${ }^{1 *}$, Alexandros Papayannis ${ }^{1}$, and Georgios Georgoussis ${ }^{2}$ \\ ${ }^{1}$ National Technical University of Athens, Laser Remote Sensing Laboratory, Physics Department, 15780 \\ Zografou, Greece, *Email: alexpant@mail.ntua.gr \\ ${ }^{2}$ Raymetrics S.A., Spartis 32, 14452 Metamorfosi, Athens, Greece
}

\begin{abstract}
In this paper we present a development of novel algorithms and techniques implemented within the Laser Remote Sensing Laboratory (LRSL) of the National Technical University of Athens (NTUA), in collaboration with Raymetrics S.A., in order to incorporate them into a 3-Dimensional (3D) lidar. The lidar is transmitting at $355 \mathrm{~nm}$ in the eye safe region and the measurements then are transposed to the visual range at $550 \mathrm{~nm}$, according to the World Meteorological Organization (WMO) and the International Civil Aviation Organization (ICAO) rules of daytime visibility. These algorithms are able to provide horizontal, slant and vertical visibility for tower aircraft controllers, meteorologists, but also from pilot's point of view. Other algorithms are also provided for detection of atmospheric layering in any given direction and vertical angle, along with the detection of the Planetary Boundary Layer Height (PBLH).
\end{abstract}

\section{THE LADDER TECHNIQUE}

There has been a lot of questioning on whether backscattering $\beta_{\text {aer }}(\lambda, R)$ and extinction $\alpha_{\text {aer }}(\lambda, R)$ coefficients can be derived from lidar slant range measurements. The well-known lidar equation for the power received at wavelength $\lambda$ from a distance $R$, is:

$P(\lambda, R)=P_{O L} \cdot \frac{A_{0}}{R^{2}} \cdot \beta(\lambda, R) \cdot \eta(\lambda) \cdot \xi(R) \cdot \Delta R \cdot \exp ^{-2 \int_{0}^{R}\left[\alpha_{M}(\lambda, r)+a_{R a y}(\lambda, r)\right] d r}$

where, $\mathrm{P}_{0 \mathrm{~L}}$ is the power of the transmitted laser pulse beam, $A_{0}$ is the diameter of the receiver's telescope, $\Delta R$ is the space resolution capability of the lidar, $\xi(\mathrm{R})$ is the geometrical form factor, $\eta(\mathrm{R})$ is the lidar optoelectronic efficiency coefficient for Mie and Rayleigh scattering, accordingly. According to Klett $[1,2]$ solved this equation for $\alpha_{\text {aer }}(\lambda, R)$ and $\beta_{\text {aer }}(\lambda, R)$ in a way where:

$a_{a e r}(\lambda, R)=\frac{\exp \left[S(R)-S\left(R_{F}\right)\right]}{\frac{1}{a\left(\lambda, R_{F}\right)}+2 \int_{R}^{R_{F}} \exp \left[S\left(R^{\prime}\right)-S\left(R_{F}\right)\right] d R^{\prime}}-a_{R a y}(\lambda, R)$ and

$$
\beta_{\text {aer }}(\lambda, R)=\frac{\exp \left[S^{\prime}(R)-S^{\prime}\left(R_{F}\right)\right]}{\frac{1}{\beta\left(\lambda, R_{F}\right)}+2 \int_{R}^{R_{F}} \frac{1}{C\left(R^{\prime}\right)} \exp \left[S^{\prime}\left(R^{\prime}\right)-S^{\prime}\left(R_{F}\right)\right] d R^{\prime}}-\beta_{R a y}(\lambda, R)
$$

where,

$$
\begin{aligned}
& S^{\prime}(R)-S^{\prime}\left(R_{F}\right)=S(R)-S\left(R_{F}\right)-\frac{16 \pi}{3} \int_{R}^{R_{F}} \beta_{R a y}\left(1-\frac{3}{8 \pi \cdot C\left(R^{\prime}\right)}\right) d R^{\prime} \\
& S(R) \equiv \ln \left[P^{\prime}(\lambda, R) \cdot R^{2}\right]=R S L S
\end{aligned}
$$

where, $\mathrm{R}_{\mathrm{F}}$ is a reference height where the values of $\alpha(\lambda, R)$ and/or $\beta(\lambda, R)$ are known (e.g. for a purely molecular atmosphere), RSLS is the Range-Squared Lidar Signal, with atmospheric and electronic noise background (BG) has been removed with:

$P^{\prime}(\lambda, R)=P(\lambda, R)-B G$

Also, $C(\lambda, R)$ is the lidar ratio:

$\mathrm{C}(\lambda, \mathrm{R})=\alpha_{\mathrm{aer}}(\lambda, \mathrm{R}) / \beta_{\mathrm{aer}}(\lambda, \mathrm{R})$

It is obvious that in vertical pointing lidars there is a reference height where we can set the values of $\alpha(\lambda, R)$ and/or $\beta(\lambda, R)$ equal to the known molecular ones, following the Boundary Point Solution techniques as shown by Klett [10]. Thus, any received lidar signal can be calibrated according to this reference value. Therefore, the reference height $R_{F}$ in Eqs. (2), (3) and (4) can be set as the vertical height at which the atmosphere is purely molecular and the signal to noise ratio is still quite high (e.g. >2-3).

By keeping the values of $\alpha(\lambda, R)$ and/or $\beta(\lambda, R)$ at the $R_{F}$, with the novel LADDER technique, we retrieve $\alpha_{\text {aer }}(\lambda, R)$ and/or $\beta_{\text {aer }}(\lambda, R)$ with the $3 \mathrm{D}$-lidar by making measurements like "stair steps" from vertical to horizontal, every $1^{\circ}$, like "walking down a ladder". In this path, we take as $\mathrm{R}_{\mathrm{F}}$ at Eq. (2) and (3) the distance, at which we abstract one or two bins (optional) for every new measurement and we keep the last value of $\alpha_{\text {aer }}(\lambda, R)$ and/or $\beta_{\text {aer }}(\lambda, R)$, at which $R_{F}$ was previously made, as the new calibrating values for $\alpha_{\text {aer }}(\lambda, R)$ and/or $\beta_{\text {aer }}(\lambda, R)$. So, if $R_{F}, \alpha_{\text {aer }}(\lambda, R), \beta_{\text {aer }}(\lambda, R)$ are the last 
known values and $R_{F-n e w}, \alpha_{\text {aer-new }}(\lambda, R), \beta_{\text {aer-new }}(\lambda, R)$, the new ones, then we have:

$\mathrm{R}_{\mathrm{F} \text { new }}=\mathrm{R}_{\mathrm{F}}-1$ bin(=7.5 m) (2 or more bins, optional) (8)

at which, according to the old values $\alpha_{\text {aer }}(\lambda, R), \beta_{\text {aer }}(\lambda, R)$ the new values $\alpha_{\text {aer-new }}(\lambda, R), \beta_{\text {aer-new }}(\lambda, R)$ are calibrating the next received signal. In this way, the measurement of every received signal and $\alpha(\lambda, R)$ and/or $\beta(\lambda, R)$ is made, taking into account the old (last) known values of these coefficients/received signals and by reducing $R_{F}$ at the same time, there is being a continually "calibration" of the values of $\alpha(\lambda, R)$ and $\beta(\lambda, R)$, from the old to the new position:

$\mathrm{R}_{\text {F-new }}<\mathrm{R}_{\mathrm{F}}$

So, during measurements, we reset the values of the signal received for every "drop" we make towards to the horizontal position and in this way, we are able to keep the values of the signal and $\alpha(\lambda, R)$ and/or $\beta(\lambda, R)$ to the "original" ones and we avoid the ambiguities by presuming a homogeneous atmosphere in every measurement, especially within long distances.

Known methods like the slope technique and/or the ratio method, are mainly using this kind of assumption (homogeneous atmospheres) to provide slant range atmospheric parameters, but in this way, the error of the measurement increases according to the unsustainability of the atmospheric conditions, by means of distance R. Here, by using the LADDER technique (Fig. 1), we saw that by resetting the values of $\alpha(\lambda, R)$ and $\beta(\lambda, R)$, we are able to use the main lidar Eq. (1), like if lidar was in vertical position and molecular measurements were made to determine $\alpha_{\text {aer }}(\lambda, R)$ and $\beta_{\text {aer }}(\lambda, R)$ at lower heights.

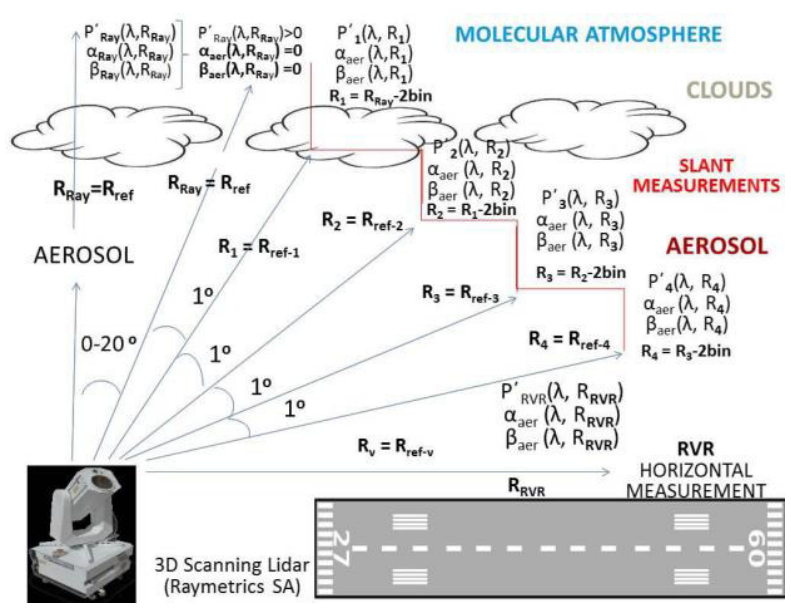

Figure 1: The LADDER technique working principle (RVRRunway Visual Range).

\section{NAVIS-T/P ALGORITHM}

After the use of denoising filters and the choice of the slant range measurement technique, the NAVIS (Novel Algorithm for VISibility measurement) - T (Tower of the Airport)/P (Pilot) is applied for further signal processing. This algorithm is able to determine the visibility of tower towards to the pilot and vice versa, according to WMO and ICAO rules of daytime visibility, at the airports. According to $[4,5,7]$ and as modified by Wright et al. [6], the values of $a_{a e r}(\lambda, R)$ and/or $\beta_{\text {aer }}(\lambda, R)$ are shown as a function of wavelength, under different atmospheric conditions (cumulus clouds, haze, etc.). A maritime model has been used in these calculations with MAPP (Modular Atmospheric Propagation Program) developed by SRI (Stanford Research Institute), because of the global nature of its application [6]. Additionally, Measures [7] also provides another figure where a number of different atmospheric conditions are taken into account (fog, haze, etc.) with extinction coefficient versus visibility at $550 \mathrm{~nm}$ at daylight.

So, a combination of these two figures is been incorporated into the NAVIS Algorithm. Then, the AOD (Aerosol Optical Depth) $(\tau)$ (Eq. 13) is been calculated from the lidar - Tower point of view and from the maximum range of the lidar signal, towards the position of lidar - Tower (Pilot's point of view) using the trapezoid method:

$\tau(0, R)=\int_{0}^{R} a\left(\lambda, R^{\prime}\right) d R^{\prime}$

where, $\mathrm{R}^{\prime}$ is the distance where $\alpha(\lambda, \mathrm{R})$ has been measured through a distance resolution of 1 bin (i.e. 7.5 $m)$. By using the values of $a_{a e r}(\lambda, R)$ and/or $\beta_{\text {aer }}(\lambda, R)$ provided in $[4,5,6,7]$, under different atmospheric conditions (cumulus clouds, haze, etc.), the visibility (Tower's and Pilot's) is been calculated and a categorization of atmospheric conditions-layering is been made at slant and/or vertical position of the lidar. Using a 3D scanning lidar system, a profile of fully atmospheric layering at different angles, azimuth and vertical, can be provided in near-real time, plus the daytime visibility, according to WMO and ICAO rules, using the empirical and well qualified, Koschmieder law (at $550 \mathrm{~nm}$ ):

$\mathrm{Vis}=3 / \alpha($ for $\varepsilon=0.05$ at $550 \mathrm{~nm})$

Vis $=3.912 / \alpha($ for $\varepsilon=0.02$ at $550 \mathrm{~nm})$

where, Vis is the visibility in $\mathrm{m}$ or $\mathrm{km}$ and $\varepsilon$ is a pure number, showing a contrast threshold, as a difference of the self-luminance of any object and the general luminance of the area viewed from a standing position. 
It is well known that the human visual range is $~ 400-$ $700 \mathrm{~nm}$, with "peaks" of visibility at $555 \mathrm{~nm}$ for daytime and $515 \mathrm{~nm}$ for night conditions, according to CIMO (Commission for Instruments and Methods of Observation) [8] for relative luminous efficiency of monochromatic radiation. By using the visibility versus the aerosol extinction coefficient at $550 \mathrm{~nm}$ [5], we are able to have a good approximation of the above required values at daytime, at $355 \mathrm{~nm}$.

Another way to do that is by using Eq. (16) for available measurements that have been made at any location with lidar at any wavelength, categorized by season and chemical atmospheric composition (AAE Absorption Ångström Exponent, which determines the wavelength dependence of absorption and EAE Extinction Ångström Exponent which is an indicator of the particle size of the atmosphere [9]), together with certain meteorological conditions, like the relative humidity (RH), temperature, rain, etc. and geographical location. The idea is that through measurements of different wavelengths of an area at different locations of interest, anyone would be able to acquire the visibility and meteorological conditions with good approximation, at a single wavelength (i.e. $355 \mathrm{~nm}$ ) (see Eqs. 17, 18), deployable at any airport:

$\alpha\left(\lambda_{1}\right) / \alpha\left(\lambda_{2}\right)=\beta\left(\lambda_{1}\right) / \beta\left(\lambda_{2}\right)$

in order to be able to acquire:

$\beta\left(\lambda_{1}\right)=C * \beta\left(\lambda_{2}\right)$

$\alpha\left(\lambda_{1}\right)=\mathrm{C} * \alpha\left(\lambda_{2}\right)$

where, $\lambda_{1}, \lambda_{2}$ are different wavelengths, for example $\lambda_{1}=355 \mathrm{~nm}$, where measurements have been taken and $\lambda_{2}=550 \mathrm{~nm}$, at which the visibility and categorization of the atmospheric conditions have been described by Measures [7]; $\mathrm{C}$ is a constant that is defined by different values, according to the calculations made at different seasons, chemical compositions of the atmosphere, at any geographical location using Eqs. 16, 17 and 18.

\section{METCON ALGORITHM}

In this algorithm METCON (METeorological CONditions), we make use of the NAVIS algorithm, to provide meteorological conditions like clouds, haze, fog, etc., versus the distance $\mathrm{R}$, for any vertical or slant range lidar measurements. The same $3 \mathrm{D}$ scanning lidar and the above-mentioned techniques and data, can be used to characterize the atmospheric conditions (fog, haze, etc.), plus the visibility. Fig. 2 shows a case study of the NAVIS and METCON algorithms, where the tower visibility from lidar's vertical pointing direction is found to be $940 \mathrm{~m}$ and the pilot's visibility from a
$3000 \mathrm{~m}$ height (distance) is of $1340 \mathrm{~m}$, in full agreement with Measures [7].

a)

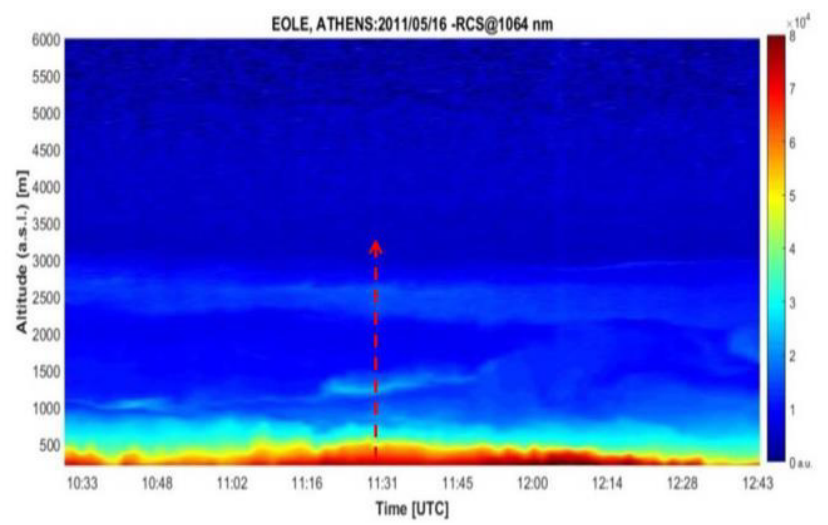

b)

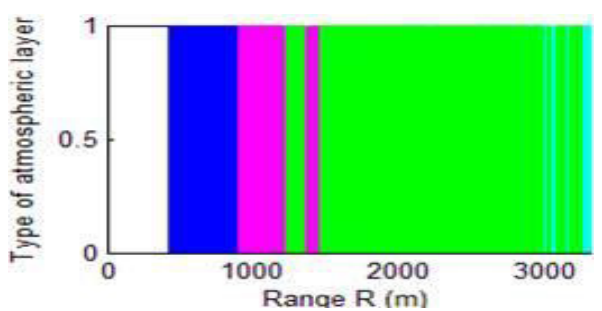

Figure 2: a) RCS signal acquired at $1064 \mathrm{~nm}$ by the LRSUNTUA (16-05-2011), b) NAVIS and METCON algorithms applied in $3 D$ lidar data pointing to the vertical (355 $\mathrm{nm}$ ) at 11:30:10 UTC, starting at $417.5 \mathrm{~m}$ above ground level up to $3000 \mathrm{~m}$. Where Blue is "Light Fog", Purple is "Thin Fog", Light Blue is "Light Haze" and Green is "Haze" [7]. Tower visibility is $940 \mathrm{~m}$ and pilot's visibility is $1340 \mathrm{~m}$ from the range of $3000 \mathrm{~m}$.

\section{VASPAT-L/D ALGORITHM}

The VASPAT-VARiable SPAce Time (VASPAT) algorithm is used to determine aerosol layering (L) and distribution (D), based on the existence of the $\beta_{\text {aer }}(\lambda, R)$ and $\alpha_{\text {aer }}(\lambda, R)$ coefficients, in $3 \mathrm{D}$ of the current atmosphere. VASPAT-L/D is pre-required for the next presented algorithm VASPAT-PBLH.

In VASPAT-L/D we take the values of $\alpha_{\text {aer }}(\lambda, R)$ or $\beta_{\text {aer }}(\lambda, R)$ versus height or slant range distance $(R)$; we then create "space filters" of different number of bins, in order to create different "tools", to further process the $\alpha_{\text {aer }}(\lambda, R)$ and/or $\beta_{\text {aer }}(\lambda, R)$ profiles. In this work we used 12 different space filters (G2 to G269) from $15 \mathrm{~m}$ (2 bins) to $2017.5 \mathrm{~m}$ (269 bins), a good space filter for the RVR (Runway Visual Range).

Afterwards, we check if the measured value of $\alpha_{\text {aer }}(\lambda, R)$ in any of these filters is greater than $4 * 10^{-5} \mathrm{~m}^{-1}$ [7]. 
Then, we check if the ratio of two consecutive average values of $\alpha_{a e r}(\lambda, R)$ in any of these "space filters" from a package of bins to the next package of equal number of bins are greater than $10 \%$. As next step, the algorithm calculates the derivatives of all space filters (dG3/dR), at every distance $(\mathrm{R})$, for vertical or slant measurements and we do the same to produce the second order derivatives $\left(d^{2} \mathrm{G} 3 / \mathrm{dR}^{2}\right)$. A series of calculations is thus been made to provide the atmosphere aerosol layering (VASPAT-L) so that we will able to have a clear vision of the 3D spatial distribution of $\alpha_{\text {aer }}(\lambda, R)$ and/or $\beta_{\text {aer }}(\lambda, R)$ around airport sites (VASPAT-D).

\section{VASPAT-PBLH ALGORITHM}

At first, we place the $3 \mathrm{D}$ scanning lidar pointing to the vertical or up to $\pm 20^{\circ}$ around the vertical. Then, we start measuring for at least $15-20 \mathrm{~min}$ in order to acquire at least 15 lidar data files. Then, we proceed to time filters. Keeping the results provided by VASPAT-L/D, we can make use of time filters after the use of the above mentioned space filters. In this case our goal is to find the PBLH with a time slot corresponding to 15-20 lidar data files (e.g. each data file is acquired within $1.5 \mathrm{~min}$.) Then, we keep track of the layering (L) and distribution (D) calculated values, and then, we make use of the layer "endings" $\left(\alpha_{\text {aer }}(\lambda, R)\right.$ negative $1^{\text {st }}$ derivative and positive $2^{\text {nd }}$ derivative). Then, we check which is the most common time depending "ending" layer in all times series within for e.g. 15-20 min period of measurements, which finally, determines the most probable PBLH.

\section{INFRASTRUCTURE}

The lidar system used for this study is the EOLE 10wavelength elastic-Raman-DIAL lidar system which is located in Athens $\left(37.96^{\circ} \mathrm{N}, 23.78^{\circ} \mathrm{E}, 220 \mathrm{~m}\right)$ at LRSLNTUA. It can perform independent measurements of $\alpha_{\text {aer }}(\lambda, R)$ and $\beta_{\text {aer }}(\lambda, R)$ (at 355,532 and $1064 \mathrm{~nm}$ ), as well as the water vapor and ozone mixing ratio in the troposphere [11]. The algorithms presented in this paper were qualified and tested (at $355 \mathrm{~nm}$ and verified by the data obtained at $1064 \mathrm{~nm}$ ) based on EOLE data [11]. These algorithms will be then implemented in the software of the 3-dimensional scanning lidar system constructed by Raymetrics S. A., based on $355 \mathrm{~nm}$ with co-polar and cross-polar detection using a $387 \mathrm{~nm} \mathrm{~N} \mathrm{~N}_{2}$ Raman detection channel, designed for aviation, meteorology and environmental applications for vertical and slant range measurements.

\section{CONCLUSIONS}

In this paper we presented several novel algorithms and techniques applied in vertical and slant range lidar measurements to calculate horizontal, slant and vertical visibility for tower aircraft controllers, meteorologists, and for the pilot's point of view, as well as for the detection of atmospheric layering and distribution of $\alpha_{\text {aer }}(\lambda, R)$ and/or $\beta_{\text {aer }}(\lambda, R)$ in 3dimensions, along with the detection of the Planetary Boundary Layer Height. We also provided a typical example based on real lidar data obtained over Athens by the EOLE system.

\section{References}

[1] Klett, J., 1981: Stable analytical inversion for processing lidar returns, Appl. Opt., 20, 211-220.

[2] Klett, J., 1985: Lidar inversion with variable backscatter extinction ratios, Appl. Opt., 24, 1638-1643.

[3] ICAO, 2005: Manual of runway visual range observing and reporting practices, Doc 9328 AN/908.

[4] Deirmendjian, D., 1964: Scattering and polarization properties of water clouds and hazes in the visible and infrared, Appl. Opt., 3 (2), 187-196.

[5] Deirmendjian, D., 1969: Electromagnetic scattering on spherical polydispersions, American Elsevier Publishing Co., Inc., New York.

[6] Wright, W. L., et al., 1966: A preliminary study of air pollution measurement by active remote sensing techniques, NASA, CR-132724 C89.

[7] Measures, R. M., 1992: Laser remote sensing. Fundamentals and applications, Krieger, sys No 9247, MEA 621.3678.

[8] CIMO (Commission for Instruments and Methods of Observation (WMO-No. 807).

[9] Russell, P. B., et al., 2010: Absorption Ångström exponent in AERONET and related data as an indicator of aerosol composition, Atmos. Chem. Phys., 10 (3), 1155-1169.

[10] Kovalev, V.A., and Eichinger, W. E.,, 2004: Elastic Lidar, Wiley Interscience.

[11] Kokkalis, P., et al., 2012: The EOLE lidar system of the National Technical University of Athens, Proc. $26^{\text {th }}$ International Laser Radar Conference, pp. 629-632, 25-29 June 2012, Porto Heli, Greece. 